\title{
The Prevalence of Febrile Seizure and Associated Factors Among Turkish Children
}

\author{
Kursat Bora Carman ${ }^{\mathrm{a}, \mathrm{b}}$, Arzu Ekicia, Sevgi Yimenicioglu ${ }^{\mathrm{a}}$, Coskun Yarara, \\ Didem Arslantas ${ }^{\mathrm{a}}$, Ayten Yakut ${ }^{\mathrm{a}}$
}

\begin{abstract}
Background: The aim of the present study was to determine the prevalence and risk factors of febrile seizure (FS) in Eskisehir province, Turkey.

Methods: The survey was conducted by family physicians and involved two steps. In the first step of research, 1,000 randomly selected 0 - 6 years old children were invited to come to their family health centers. A specific questionnaire was administered to the parents during face to face sessions. The children who had had a history of FS were referred to the university hospital where detailed medical histories were taken and neurological examinations were conducted.
\end{abstract}

Results: The prevalence of FS was calculated to be $2.57 \%$. The ratio of male to female was 1:1. The relationships between a positive history of FS and study variables were analyzed through logistic regression. It was found that attendance to day care center affects the prevalence of FS, with the risk of FS being 19.35 times higher if child attends to day care. Also familial history of FS and consanguinity of parents increase the risk that their children will have FS 7.52 and 13.1 times higher, respectively.

Conclusions: FS is still a frequent problem in pediatric practice. Although the prevalence of FS might vary according to the methodology of study, this present study found that the prevalence of FS was $2.57 \%$ among Turkish children.

Keywords: Febrile seizure; Prevalence factor; Children

Manuscript accepted for publication February 20, 2014

${ }^{a}$ Department of Pediatric Neurology, Eskisehir Osmangazi University Hospital, Eskisehir, Turkey

${ }^{\mathrm{b}}$ Corresponding author: Kursat Bora Carman, Batikent Mah. Vehbi

Dincerler Cad. Sena Apt No. 26 D9, Sehitkamil, 27000 Gaziantep,

Turkey. Email: bcarman@gmail.com

doi: http://dx.doi.org/10.14740/ijcp134w

\section{Introduction}

Febrile seizure (FS) is defined as a seizure event of infancy and childhood that is associated with fever; definition excludes prior unprovoked seizures and seizures associated with central nervous system (CNS) infection, electrolyte imbalance and other acute symptomatic events. FSs are classified as either simple or complex. Simple FSs include those that are isolated, generalized and brief. Complex FSs are focal, multiple (more than one seizure during the febrile illness), or prolonged (lasting longer than $15 \mathrm{~min}$ ).

Epidemiologic studies have indicated that FSs are agespecific occurrences, with most episodes occurring when children between the ages of 3 months and 5 years. FSs can occur in children as young as 1 month of age $[1,2]$.

Although FS is the most common seizure disorder in childhood, the prevalence and incidence of FS varies by geographic location $[3,4]$. The reported incidence of FS in children before age of 5 varies widely from $1 \%$ in China and $2 \%$ in Taiwan to $8 \%$ in Japan and $14 \%$ in Guam. In the United States and Europe, the incidence ranges from $2 \%$ to $5 \%$. Similar to the incidence, different FS prevalence rates have been reported. Generally the prevalence of FS is lower in western countries $(1.7 \%$ in the United States, $3.9 \%$ in Holland) than eastern world (9.3\% in Japan) [4-9]. Similar to these varying prevalence rates reported from world, the results of previously performed researches in Turkey also range between $4 \%$ and $12.4 \%[10,11]$. The methodological differences could be a factor in variation [12].

The aim of the present study is to search the prevalence of FS and accompanying factors among children in Turkey.

\section{Materials and Methods}

This cross-sectional study was performed in Turkey's Eskisehir province, which is located in the central region of country (Fig. 1).

The study was carried out from September to December 2011. According to Turkish health system everyone living in Eskisehir is registered in the family health registration sys- 


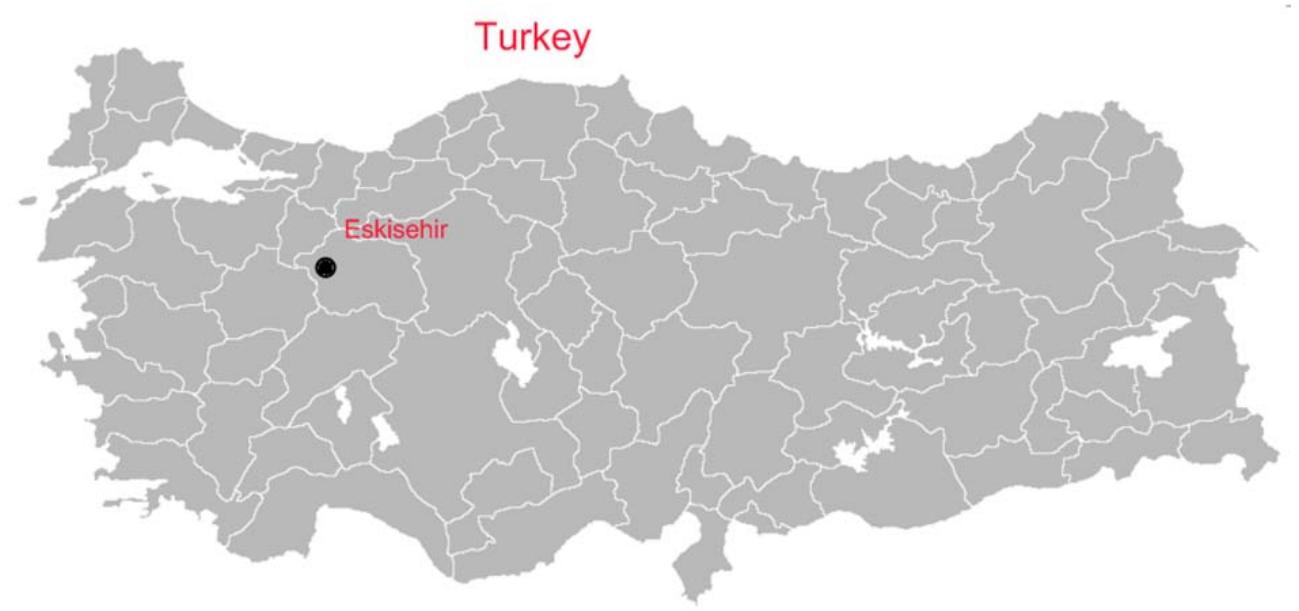

Figure 1. The geographic location of Eskisehir. This cross-sectional study was performed in Turkey's Eskisehir province, which is located in the central region of country.

tem and has a family physician. The survey was conducted by family physicians and involved two steps. In the first step of research, 1,000 randomly selected 0 - 6 years old children were invited to come to their family health centers. A specific questionnaire which was administered to the parents during face to face sessions, involving two distinct parts. The first part investigated the medical and demographic characteristics of their children, and the second surveyed the features

Table 1. Risk Factors for Febrile Seizure Using Univariate Analysis (Total $=933$ )

\begin{tabular}{|c|c|c|c|}
\hline & FS (+) n (\%) & FS (-) n (\%) & P value \\
\hline Prematurity & $6(25)$ & $77(8.4)$ & $<0.05$ \\
\hline Positive family history for FS & $7(29.1)$ & $49(5.4)$ & $<0.05$ \\
\hline Day care attendance & $6(16)$ & $32(2)$ & $<0.05$ \\
\hline \multicolumn{4}{|l|}{ Mother's education } \\
\hline Illiterate & $4(16.6)$ & $74(8.1)$ & $<0.05$ \\
\hline Primary school & $8(33.3)$ & $505(55.5)$ & $>0.05$ \\
\hline High school & $11(45.8)$ & $225(25.7)$ & $>0.05$ \\
\hline University & $1(4.1)$ & $105(11.5)$ & $>0.05$ \\
\hline The mean age (month) & $36.9 \pm 16.8$ & $35.7 \pm 19.7$ & $>0.05$ \\
\hline Average number of brothers/sisters & $2.16 \pm 1.0$ & $1.84 \pm 1.1$ & $>0.05$ \\
\hline Family size (number of persons in family) & $4.54 \pm 1.48$ & $4.21 \pm 1.48$ & $>0.05$ \\
\hline Birth weight (g) & $3,138 \pm 641$ & $3,131 \pm 457$ & $>0.05$ \\
\hline Mean day of ICU & $14 \pm 13.4$ & $5 \pm 5.5$ & $>0.05$ \\
\hline Maternal age & $29.45 \pm 6.1$ & $28.74 \pm 5.4$ & $>0.05$ \\
\hline Paternal age & $31.66 \pm 6.6$ & $32.94 \pm 6$ & $>0.05$ \\
\hline
\end{tabular}


Table 2. Logistic Regression Analysis of Factors Related to Febrile Seizure

\begin{tabular}{llll}
\hline & B (odd ratio) & $\mathbf{9 5 \%}$ CI & P value \\
\hline Prematurity & 9.11 & $0.82-100.73$ & 0.07 \\
Neonatal ICU & 1.65 & $0.50-5.45$ & 0.04 \\
Day care & 19.35 & $5.89-63.49$ & 0.00 \\
Consanguinity & 13.10 & $4.12-41.62$ & 0.00 \\
Familial history of FS & 7.52 & $2.60-21.74$ & 0.00 \\
\hline
\end{tabular}

of each child's family. The children who had had a history of FS were referred to the university hospital where detailed medical histories were taken and neurological examinations were conducted.

Statistical analyses were performed using the Statistical Package for the Social Sciences (SPSS, Chicago, IL, USA). The research looked at the prevalence of FS among the children and any familial factors. Student's $t$ test and Fisher's exact test were used, as well as the Chi square test and backward stepwise logistic regression tests. $\mathrm{P}<0.05$ was considered statistically significant.

\section{Results}

Of the 1,000 invited children, 933 (93.3\%) participated and all of them remained through to final analysis. Their genders were equally distributed ( $48.6 \%$ males and $51.4 \%$ females). The mean age of the study group was $35.78 \pm 19.65$ month.

\section{Prevalence}

Twenty-four children had FS. Its prevalence was calculated to be $2.57 \%$. The ratio of male to female was $1: 1$ and mean age was $36.91 \pm 16.83$ month.

\section{Socio-demographic features}

The characteristics socio-demographic features of the study group and the results of univariate analysis are summarized in Table 1. Prematurity, family history of FS, attendance to day care center, consanguinity of their parents and the educational status of the mothers significantly affected the frequency of FS. Factors that were to be non-significant included the mean age of children, average number of brothers/sisters, birth weight, mean day of stay in ICU, the mean ages of parents and the size of families (average number of people living in the same house). The relationships between a positive history of FS and study variables were analyzed through logistic regression (Table 2).
The study reveals that attendance to day care center affects the prevalence of FS, with the risk of FS being 19.35 times higher if child attends to day care. Also familial history of FS and consanguinity of parents increase the risk of their children whose FS is 7.52 and 13.1 times higher, respectively.

\section{The characteristics of children with FS}

Based on the parents' reports, simple types of FS occurred in $20(83.3 \%)$ children. Eighteen children had had single seizure and in six children seizure repeated. The mean age of first seizure was $18.87 \pm 11.85$ month. The mean time between first and second attacks was 3.3 month and all second seizures had occurred within following 2 years.

\section{Discussion}

In the present study conducted in Turkey's Eskisehir province, the prevalence of FS was found to be $2.57 \%$. To determine the risk of any disease (such as FS) in a given population, two epidemiological approaches can be considered: 1) a cumulative incidence study of a cohort of live birth and 2) a prevalence survey among subjects at an age beyond the typical risk age [12]. To perform researches related with incidence of FS, the fundamentals are a well developed health organization and medical recording system, and only possible in western countries. The incidence of FS varies by geographic location: incidences up to $8.8 \%$ and $14 \%$ have been reported [13]. The assessment of prevalence is much practical than incidence. Epidemiologic studies of FS provide a wide spectrum of the prevalence of FS $(0.1-15 \%)$ [3, 4]. In order to explain this great difference between previously reported prevalence rates, Tsuboi suggested the following explanations [14]: 1) the use of different definitions of FSs, 2) different methods of case ascertainment, and 3) true differences in prevalence rates between countries. In this cross-sectional study conducted by family physicians, a specific questionnaire was administered to the parents during 
face to face sessions. It has been stated that the most reliable method is ascertainment by clinical examination of all subjects to be investigated by a physician [15]. We believe that the strategy used in the present study comes closest to this ideal. The accuracy of research might be affected by type of study whether it was conducted prospectively or retrospectively. Sillanpaa et al reported that the incidences of FS in prospectively and retrospectively were $7.1 \%$ and $5.6 \%$ [13], respectively. The retrospectively achieved rate of FS in the current study $(2.57 \%)$ is comparable with rates from retrospective studies in industrialized countries.

A number of factors have been known to increase a child's risk of having a first FS [4]. Using multivariate analysis, Bethune et al identified several important predictors of first FSs, including family history, attendance at day care and a neonatal discharge time of 28 days or more [16]. The result of present study also showed that family history of FS, consanguinity and attendance at day care are factors that increase risk for FS 7.52, 13.10, 19.35 times, respectively. Although Mahyar et al reported similar to us prematurity is not a risk factor [17]. Vestrgaard and Christensen revealed that children born prematurely had an increased risk of FSs compared with children born at term, and the adjusted RR was 1.4 [18]. The FS was more common in children of illiterate mothers. Forsgren et al revealed that mother's educational status was a risk factor [19]. If parents do not have proper knowledge on fever management, they would take incorrect steps to control fever.

\section{Conclusion}

FS is still a frequent problem in pediatric practice. Although the prevalence of FS might vary according to the methodology of study, this present study found that the prevalence of FS was $2.57 \%$ among Turkish children. The attendance to day care center, familial history of FS and consanguinity of parents were risk factors of FS on multivariate analysis.

\section{References}

1. Febrile seizures. Consens Dev Conf Summ Natl Inst Health. 1980;3:7-11.

2. Guidelines for epidemiologic studies on epilepsy. Commission on Epidemiology and Prognosis, International League Against Epilepsy. Epilepsia. 1993;34(4):592596.

3. Shinnar S, Glauser TA. Febrile seizures. J Child Neurol. 2002;17(Suppl 1):S44-52.

4. Shinnar S. Febrile seizures. In Swaiman KF, Ashwal S,
Ferriero DM, eds. Pediatric Neurology: Principles and Practice. 4th ed. St. Louis, MO: Mobsy; 2006:10791090.

5. Annegers JF, Hauser WA, Shirts SB, Kurland LT. Factors prognostic of unprovoked seizures after febrile convulsions. N Engl J Med. 1987;316(9):493-498.

6. Berg AT, Shinnar S, Hauser WA, Alemany M, Shapiro ED, Salomon ME, Crain EF. A prospective study of recurrent febrile seizures. N Engl J Med. 1992;327(16):11221127.

7. Berg AT, Shinnar S. Complex febrile seizures. Epilepsia. 1996;37(2):126-133.

8. Strafsrom CE. The incidence and prevalence of febrile seizures. In: Baram TZ, Shinnar S, eds. Febrile seizures. San Diego, CA: Academic Press; 2002:1-25.

9. Leung AK, Robson WL. Febrile seizures. J Pediatr Health Care. 2007;21(4):250-255.

10. Okan N, Okan M, Eralp O, Aytekin AH. The prevalence of neurological disorders among children in Gemlik (Turkey). Dev Med Child Neurol. 1995;37(7):597-603.

11. Karabiber H, Yakinci C, Durmaz Y, Kutlu O, Soylu H. Prevalence of epilepsy in 3637 children of primary school age in the Province of Malatya, Turkey. J Trop Pediatr. 2001;47(5):317-318.

12. Sander JW, Shorvon SD. Incidence and prevalence studies in epilepsy and their methodological problems: a review. J Neurol Neurosurg Psychiatry. 1987;50(7):829839.

13. Sillanpaa M, Camfield P, Camfield C, Haataja L, Aromaa M, Helenius H, Rautava $P$, et al. Incidence of febrile seizures in Finland: prospective population-based study. Pediatr Neurol. 2008;38(6):391-394.

14. Tsuboi T. Epidemiology of febrile and afebrile convulsions in children in Japan. Neurology. 1984;34(2):175181.

15. Tsuboi T. Seizures of childhood. A population-based and clinic-based study. Acta Neurol Scand Suppl. 1986;110:1-237.

16. Bethune P, Gordon K, Dooley J, Camfield C, Camfield P. Which child will have a febrile seizure? Am J Dis Child. 1993;147(1):35-39.

17. Mahyar A, Ayazi P, Fallahi M, Javadi A. Correlation between serum selenium level and febrile seizures. Pediatr Neurol. 2010;43(5):331-334.

18. Vestergaard M, Christensen J. Register-based studies on febrile seizures in Denmark. Brain Dev. 2009;31(5):372377.

19. Forsgren L, Sidenvall R, Blomquist HK, Heijbel J, Nystrom L. An incident case-referent study of febrile convulsions in children: genetical and social aspects. Neuropediatrics. 1990;21(3):153-159. 